\title{
ON THE ICONICITY OF THE Y-HANDSHAPE
}

\author{
Maria MERTZANI*
}

- ABSTRACT: As part of a two-year research project, the study examines the diagrammatic iconicity of the Y-handshape of two non-cognate sign languages; the American Sign Language and Greek Sign Language. In a sample of sixty-four signs, and through a close reading approach, it demonstrates the association of the specific handshape with real-world referents that have simultaneously a round and angular form (e.g. cylinder, cone), or only an angular/linear shape. It also shows its historic association with the ancient traditional sign mano cornuta, addressing its metonymy in meanings relating to quantity, earth, life, loss, light and cavity.

- KEYWORDS: Y-handshape. mano cornuta. iconicity. American Sign Language. Greek Sign Language.

\section{Introduction}

The study is part of a two-year post-doctoral project (February 2014 - March 2016) on the symbolism of closed phonology of natural languages (spoken and signed), which was conducted in the Federal University of Pelotas (UFPEL), Pelotas - RS, Brasil. In particular, it examined the Y-handshape as a closed phoneme of signed languages (SLs), next to A-handshape and its allophones (e.g. the S-handshape, Å-handshape), on the basis of diagrammatic iconicity, according to which forms (e.g. phonemes) are diagrams or icons that "represent the relations of the parts of one thing by analogous relations in their own parts" (WAUGH, 1994, p.56), thus resembling and/or imitating objects in respect to similarity of relations among their parts. Hence, in SLs and spoken languages there is iconicity in their lexicon, and key to its understanding is to compare their structured correspondences (EMMOREY, 2014).

A connection between form, meaning and real-world referents is possible through symbolism when content-free units convey meaning in certain linguistic contexts (AURACHER et al., 2011; PERNISS; THOMPSON; VIGLIOCCO, 2010). Therefore, each object can have an inherently correct name known from the object itself, from its denotata (PERNISS; THOMPSON; VIGLIOCCO, 2010). The study adopts the typology of symbolism by Hinton, Nichols and Ohala $(1994$, p.4) as the direct linkage between form and meaning, where certain phonemes and suprasegmentals "are chosen to consistently represent visual, tactile, or proprioceptive properties of objects, such

\footnotetext{
* Universidade Federal de Pelotas (UFPEL), Centro de Letras e Comunicação, Pelotas - Rio Grande do Sul - Brasil. maria.d.mertzani@gmail.com. ORCID: 0000-0002-4617-9144
} 
as size or shape." This relationship is more transparent in SLs, as they make use of iconicity to a much greater extent than spoken languages (TAUB, 2001). Their visualmanual modality provide "richer resources for creating structural similarities between phonological form and meaning," since their visual three-dimensional modality "allows for iconic expression of a wide range of basic conceptual structures, such as object and human actions, movements, locations, and shapes" (EMMOREY, 2014, p.1574).

The investigation of such analogy is based on the fact that visual objects are characterised by boundaries or contours that delimit their geometric properties in visual space (e.g. size, shape, location) (BREITMEYER; TAPIA, 2011), and their coding derives from combinations "of a modest number of categorized primitives based on simple perceptual contrasts" (BIEDERMAN, 1987, p.145), which may permit canonical configurations. It was then hypothesised that the Y-handshape is culturally selected to resemble the contours found in natural scenes, especially those of round real-world referents.

\section{The Study}

Although the Y-handshape is a marked handshape (in terms of its proportional frequency; it does not occur frequently) in most SLs (cf. VAN DER KOOIJ; CRASBORN, 2016) as in American Sign Language (ASL) and Greek Sign Language (GSL), this paper aims to show some convergent mapping in certain context and for similar and/ or the same referents. For the purposes of this examination, the following dictionaries were used: (i) the Online Dictionary of Concepts in GSL by the Educational Policy Institute (2013), and the Dictionary of Sign Language by Magganaris (1998); and (ii) the American Sign Language Handshape Dictionary by Tennant and Gluszak Brown (1998), from which 64 signs involving the Y-handshape (in the dominant and nondominant hands) were extracted (see Appendix), following the order of appearance in the dictionaries.

The collected signs were also cross-checked with the following dictionaries: for GSL, with the Dictionary of Sign Language by Logiadis and Logiadi (1985), and the System of Greek Signs by Triantafyllides (1990); and for ASL, with the American Sign Language Dictionary by Costello (2008), and the A Historical and Etymological Dictionary of American Sign Language by Shaw and Delaporte (2015). Furthermore, the online dictionary Spreadthesign (2012) was used, allowing the lexical items of the two SLs to be compared globally.

Data are reported qualitatively, based on a close reading approach (KANEKO; SUTTON-SPENCE, 2012) that involved the three-stage analogue-building model (TAUB, 2004, p.44) for demonstrating the relationship between the Y-handshape, its meaning and referents. In doing so, three stages were followed: the image selection of a mental image that is associated with the original concept/referent; the schematisation of essential features of the image; and the encoding of the resulting schema; that is, the 
Y-handshape itself. Data also involved descriptive statistics due to the small sample of the study.

Table 1 - ASL meanings and their frequency.

\begin{tabular}{|c|c|}
\hline ASL MEANINGS & TOTAL \\
\hline Quantity, measure, similarity, time & 10 \\
\hline Land, country, place, present & 5 \\
\hline Head, mental activity, edge & 4 \\
\hline Cavity, volume & 4 \\
\hline Loss, bad, negative & 4 \\
\hline Life, animals & 3 \\
\hline Light, colors & 2 \\
\hline Motion & 2 \\
\hline Other: liquids; happiness & 2 \\
\hline TOTAL: & 36 \\
\hline
\end{tabular}

Source: author's elaboration.

\section{Results}

As Tables 1 and 2 display, the Y-handshape in ASL $(n=36)$ and GSL $(n=28)$ is used in almost the same semantic domains, although its frequency is differentiated in each SL. In ASL, the handshape more frequently refers to meanings of 'quantity, measurement and time' (e.g. MEASURE, YESTERDAY, OBESE), and 'land, location, reference and presence' (e.g. COUNTRY, NEW YORK, PRESENTLY), whereas in GSL, it appears more frequently in meanings of 'motion' (e.g. PLAY, GO-FOR-A-WALK, TO-KNIT) 'quantity, measurement and time' (e.g. ETERNITY, THURSDAY), and 'life/animals' (e.g. COW, ANIMALS, MAMMAL). The comparison reveals common domains although the articulation of the majority of signs differs.

Table 2 - GSL meanings and their frequency.

\begin{tabular}{|c|c|}
\hline GSL MEANINGS & TOTAL \\
\hline Motion & 5 \\
\hline Quantity, measure, time & 5 \\
\hline Life, animals & 4 \\
\hline Land, place, presence & 3 \\
\hline Loss, bad, negative & 3 \\
\hline Community & 3 \\
\hline Other: cavity, happiness, head & 3 \\
\hline Light, colors & 2 \\
\hline TOTAL: & 28 \\
\hline
\end{tabular}

Source: author's elaboration. 
The exception is the sign cow as it is the same in both SLs, although its execution slightly differs in the movement of the handshape (Fig. 1). Overall, the Y-handshape appears to express animals, especially mammals (e.g. in ASL, BULL, HIPPOPOTAMUS, RHINOCEROS), a result that also indicates a preference of both ASL and GSL towards closed phonology for the representation of animals and living organisms. In this case, the Y-handshape corresponds to i.e., the open mouth of the animal (the hippopotamus), to the horn of rhinoceros, and/or to the horns of a cow or bull (Fig. 2), in other words, to referents whose contours visually form a roundish schema, and/or carry roundness such as the conical horns of the animals. In GSL, the signs ANIMALS and MAMMAL are performed by this specific handshape, perhaps due to metonymy referring to cattle. In ASL, the horns are also performed by the S-handshape (COSTELLO, 2008, p.234), an allophone of the A-handshape, which also imitates the roundness of its referent. Both hands on a closed O-handshape imitate the holding of the horns, move upward while forming a small arc, and end into the S-handshape (see Fig. 1). 
Figure 1 - The analogue building model for the sign Cow. ${ }^{1}$

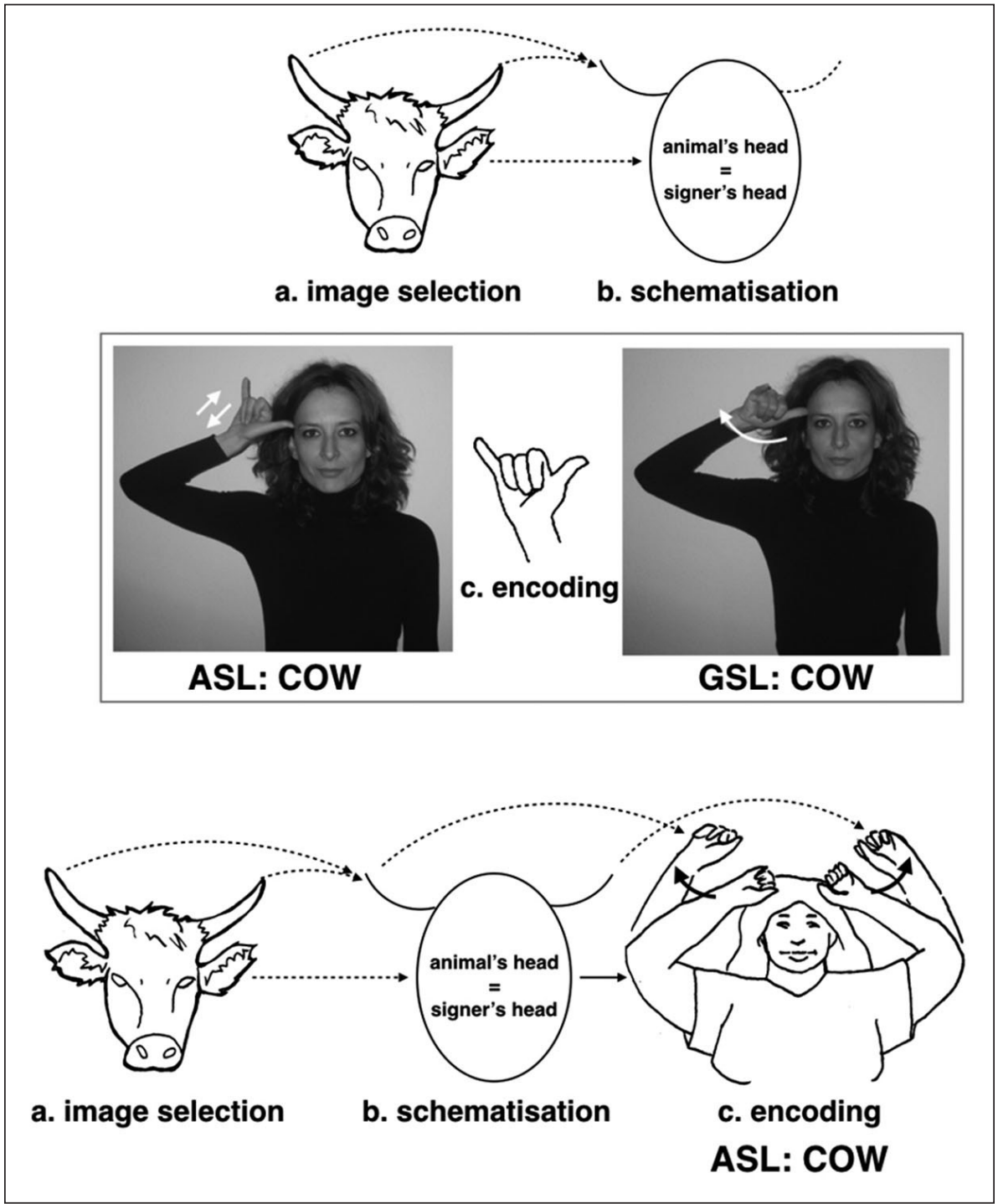

Source: author's elaboration.

In both SLs, the sign COW is also two-handed, usually though is executed as one-handed. In GSL, it is also a compound by the signs HORN (articulated with the Y-handshape) and MILK (articulated with the S-handshape), describing the head of the animal and its milking. 
Figure 2 - The analogue building model for the

ASL HIPPOPOTAMUS and RHINOCEROS ${ }^{2}$

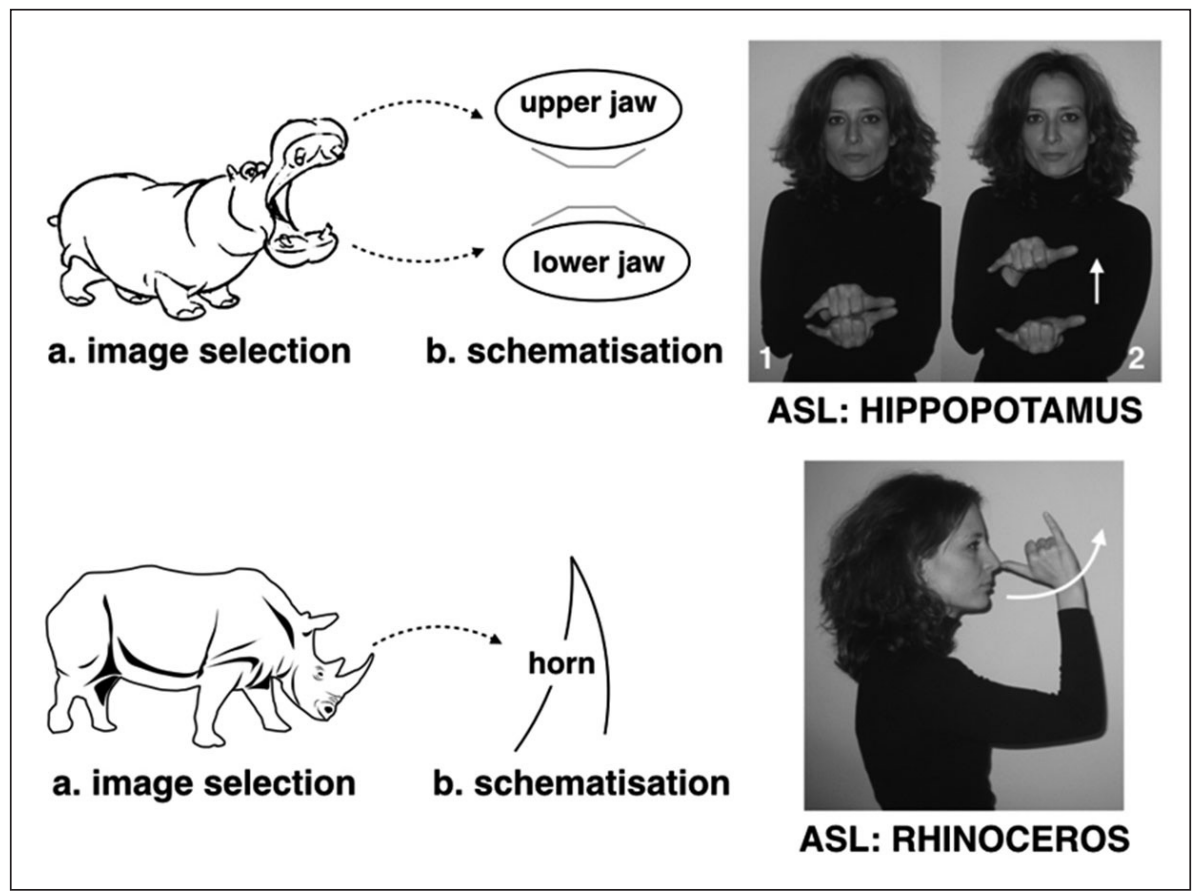

Source: author's elaboration.

Based on the three-stage analogue-building model, the Y-handshape in the 'land, location, reference and presence' domain, demonstrates its association with 'animal/ life' symbolism. For example, in the signs SPAIN $^{3}$ (in GSL) and THE-NETHERLANDS ${ }^{4}$ (in ASL), it represents the head of a cow/bull, thus referring to the bull fighting in Spain, and the cattle for dairy farming in the Netherlands. In GSL, the sign ATHENS is recorded to be expressed by both the Y- handshape (LOGIADIS; LOGIADI, 1985) and/or A-handshape (Fig. 3), a finding that attests their alternate function. In this case, their closed phonology represents the place, the city (Athens) in the middle of the B-handshape, ${ }^{5}$ denoting collectivity (e.g. the city as a group of people), and thus an entity. Their pointing at the centre of the B-handshape indicates the country's epicentre as a capital city.

In HIPPOPOTAMUS, the fingers of the Y-handshape match the animal's protruding teeth.

This is an old sign recorded by Triantafyllides (1990, p.104). Currently, the sign has changed and is articulated with the A-handshape.

4 Another version of this sign refers to the traditional hat of its people.

5 Both handshapes denote 'land/place' but the difference is on the primacy of the hand. The B-handshape has a secondary, explanatory role in relation to the Y-handshape of the main hand. It is subordinate, serving as the locus where the main referent (Athens) is located. 
Figure 3 - The analogue building model for the GSL ATHENS.

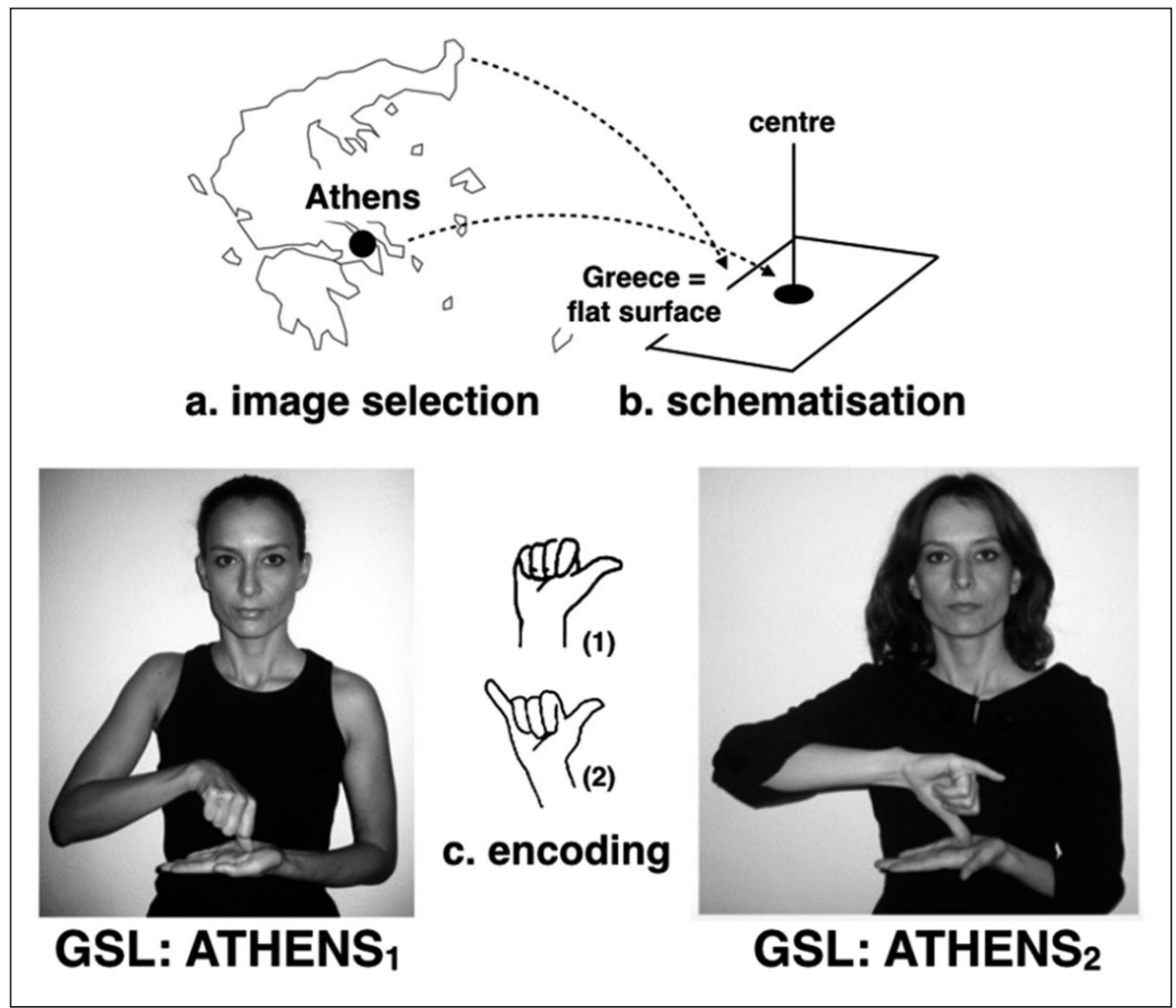

Source: author's elaboration.

In ASL, the sign COUNTRY (or LAND) refers to a state or nation or its territory, and to rural areas, as opposed to cities and towns (COSTELLO, 2008). In fact, its etymology is based on the French sign CAMPAIGNE (countryside), which imitates the action of harvesting, the cutting of wheat with a sickle (see Fig. 4). This ASL sign (COUNTRY) with the Y-handshape is the second, alternate version of the one with the B-handshape, which also comes from its corresponding French (cf. SHAW; DELAPORTE, 2015), imitating the blade surface of the sickle. The fact that the domain 'earth/land' is expressed by a closed handshape (as the Y-handshape is), corroborates current sound symbolism research that shows closed phonemes (middle-to-back) to connect to meanings of land, largeness, and/or magnitude (MIALL, 2001; NOBILE, 2011). 
Figure 4 - The etymology of the ASL COUNTRY ${ }^{6}$

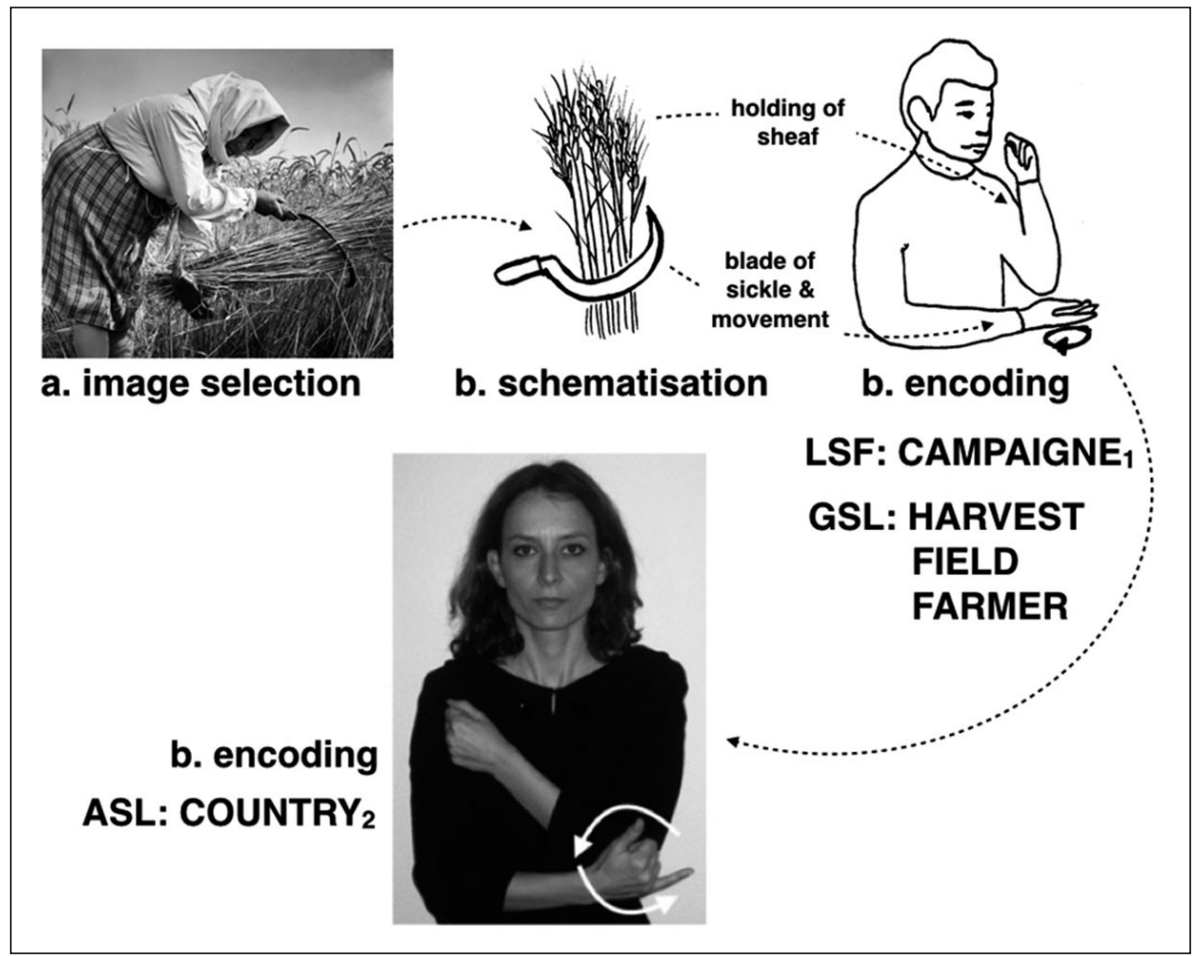

Source: author's elaboration.

The domain 'community' appears only in GSL, in which the Y-handshape denotes family relations such as COUSIN and RELATIVES. This is another indication of the mapping of closed phonology to meanings of groups and social relationship (see above for ATHENS), which, to a certain extent, associate with the domain 'life' as they refer to man overall (and thus, to an entity). For GSL, the closer the family relation, the closer the phonology of the sign. For example, first degree family relations (e.g. MOTHER, FATHER) are performed by the A-handshape (on the head), phonologically a closer handshape than the Y-handshape, which expresses second and/or third degree relative (Fig. 5).

The sign originates from the French CAMPAIGNE (countryside), which is exactly the same in GSL for HARVEST, FIELD, and FARMER. 
Figure 5 - Examples of the Y-handshape in the community domain ${ }^{7}$

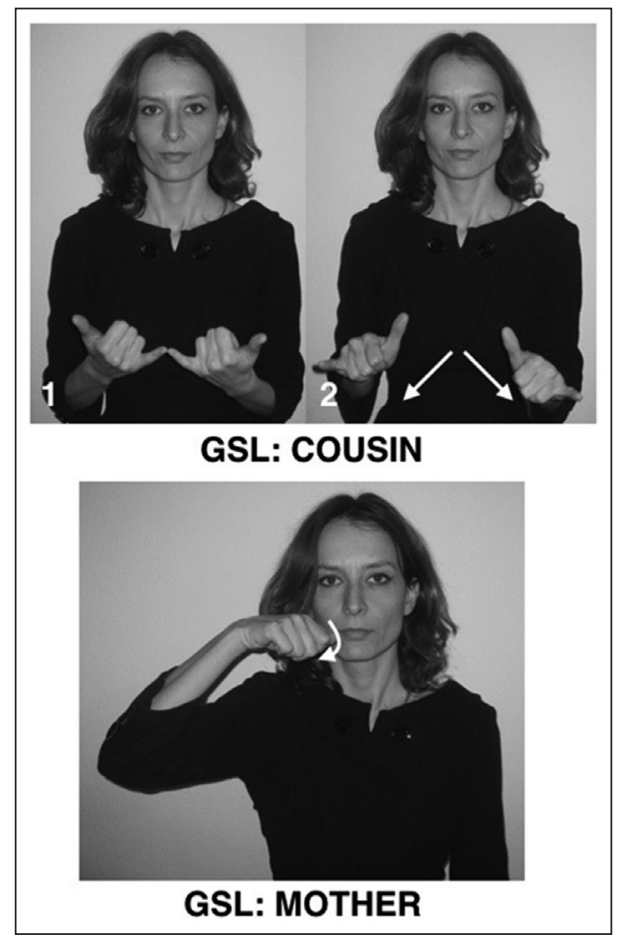

Source: author's elaboration.

Phonological correspondence also occurs in the domain 'cavity-volume' for the signS AIRPLANE and TELEPHONE, in which the closed part of the handshape imitates the body volume of the specific referents, and its extended fingers, the wings of the plane craft and/or the telephone handset. In ASL, the H-handshape also alternates with the Y-handshape for the articulation of AIRPLANE. In this domain, the Y-handshape also imitates the handling of the referent (e.g. in ASL, IRON and SHAVE), thus partially mapping to its roundness, considering i.e., the round shape of the handle of an iron and/or the cylindrical shape of the aircraft (cf. BIEDERMANN, 1987, p.132). Although there is some variety in the signing of ASL IRON, in GSL it is signed with the Â-handshape, showing this exact handling. For the sign SHAVE, both handshapes appear, depending on the form of the razor, although the movement differs (Fig. 6). This handshape alternation also demonstrates the strong analogy of the Y-handshape to the form of the referent.

The closeness of the handshape indicates a centripetal direction toward the user, and on the head (e.g. holding the spoon for feeding for the sign MOTHER). The Y-handshape, is phonologically more open than the A-handshape, denoting a direction away from self, and faction. 
Figure 6 - The signs SHAVE in ASL and GSL ${ }^{8}$

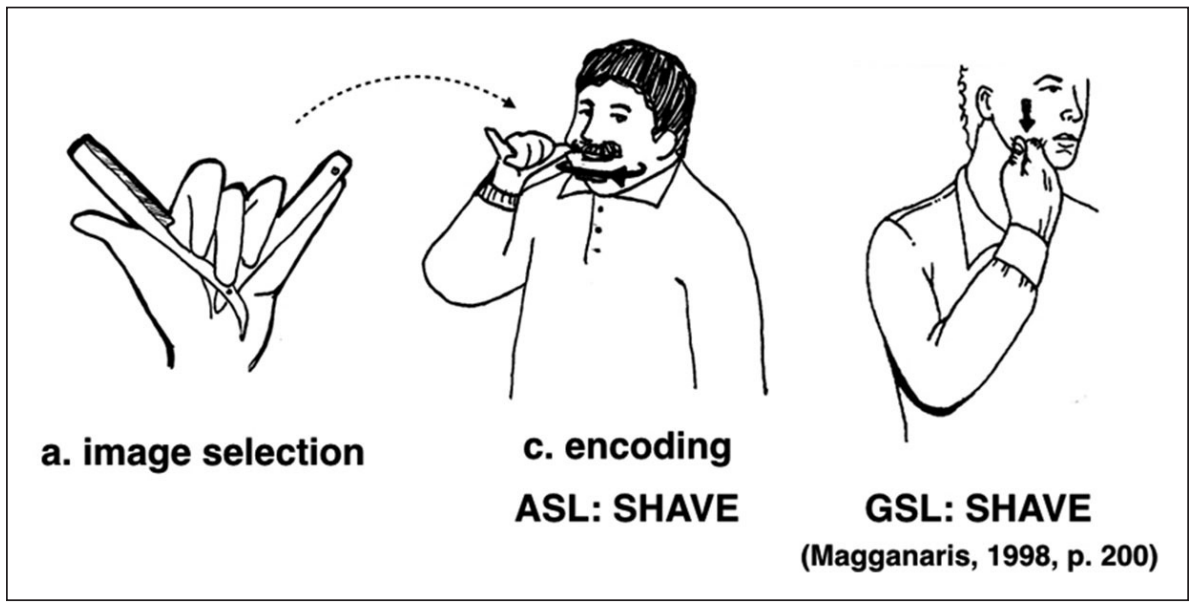

Source: author's elaboration.

In the domain 'quantity, measurement and time' the Y-handshape appears firstly in time concepts. For example, the sign YET/STILL (it conveys the concept of continuity in the future; cf. COSTELLO, 2008; SHAW; DELAPORTE, 2015) appears in both SLs regardless its different articulation. In addition, the sign YESTERDAY in ASL appears with both the A-handshape and Y-handshape, whereas in GSL, with the A-handshape only. In other cases, as in GSL for THURSDAY, the Y-handshape is supported to represent an ancient form of the number five (TRIANTAFYLLIDES, 1991, p.101), which is found in other European SLs (e.g. Romanian, Czech, French; cf. SPREADTHESIGN, 2012) (Fig. 7), and in the Hawaiian traditional shaka sign that stands for number five as well. The most likely explanation for such correspondence was the ancient widespread worship of Venus ${ }^{9}$ (as a morning and an evening star, corresponding to the sun and moon), whose five-pointed star symbol stood for the number five. Therefore, the handshape, the well-known mano cornuta, represented her as the cow goddess (cf. MERTZANI, 2017). Interestingly, the ASL THURSDAY (and TUESDAY) is performed with the T-handshape (also a closed handshape) (COSTELLO, 2008), which in antiquity was known as mano fico (> Latin, fica: vulva), the handshape of Venus too.

In GSL, the A-handshape is used when the sign refers to the shaving machine. When the signing refers to the razor of the image, the Y-handshape is used.

9 Archaeological hand artifacts show that the thumb and the small finger, parts of the Y-handshape, were devoted to Venus, the sun and moon, and involved horned depictions such as a female head with horns (ELWORTHY, 1900). 
Figure 7 - The Y-handshape in the sign THURSDAY

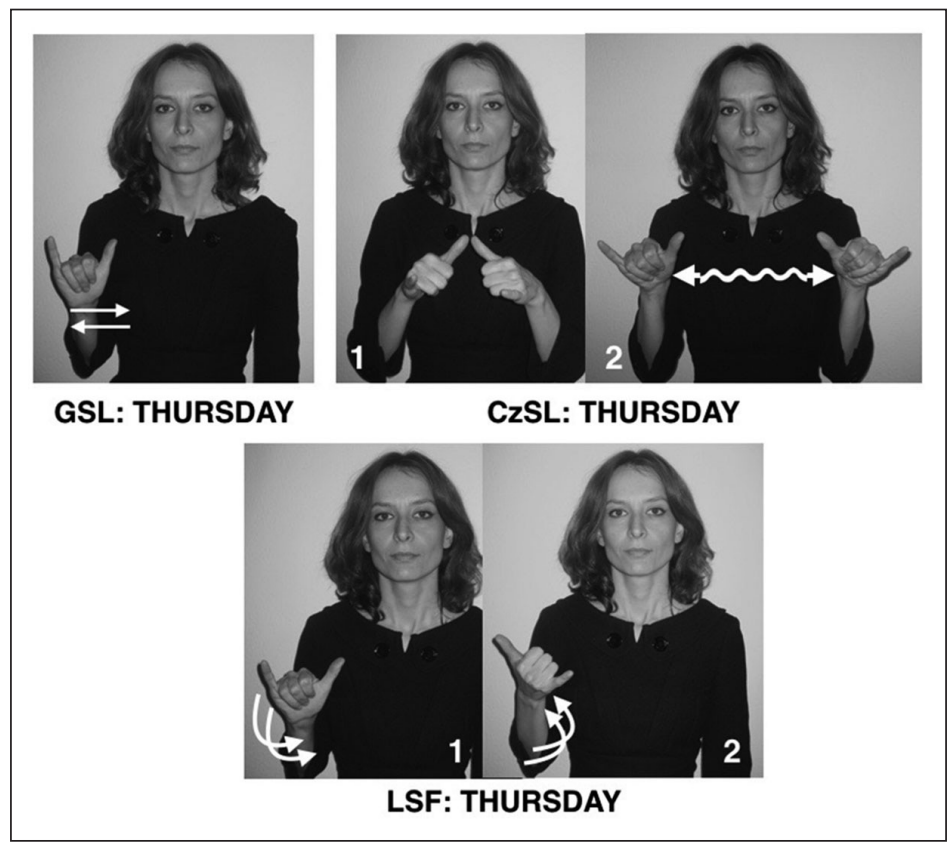

Source: author's elaboration.

In GSL, the summer months JUNE and JULY are recorded to be signed by the Y-handshape (LOGIADIS; LOGIADI, 1985, p.72), although their initialised forms are currently preferred. Moreover, Triantafyllides (1990, p.95) documented June with the $\AA$-handshape, suggesting its origin on the school competition ${ }^{10}$ at the end of the school year. Following this interpretation, the handshapes seem to mean two opposing entities, most probably, considering the older recording of the Y-handshape, two horned animals, as it occurs in the ASL sign ANTAGONISTIC (see below). This notion of entity can be claimed for the sign ETERNITY, as if one moves front to the future. Under the 'measure' meanings (in ASL, MEASURE, RULER, SIZE), the Y-handshape relates again to standard units, as in GSL to number five, and/or to instruments marking the units (e.g. the ruler).

In the domain 'motion,' the Y-handshape associates with meanings like 'taking a walk' and 'play' (e.g. WALK, PLAY). In these, the Y-handshape represents the whole entity acting (a human, an animal, etc.), as is found in other SLs (FRISBERG, 1979; HERLOFSKY, 2007; TANG; YANG, 2007; TANG, 2003). Iconicity is stronger when the representation involves machinery/instruments (cf. PADDEN; MEIR; HWANG, et al., 2014), as in ASL DRAFTING/ENGINEERING and TO-KNIT, where handling is also involved (e.g. the handling of knitting needles, or screwing). With regards to the sign

10 In Italian Sign Language, June also denotes competition, performed by closed handshapes; either by A-handshape or X-handshape (SPREADTHESIGN, 2012). 
PLAY in ASL, Shaw and Delaporte (2015, p.203) link its etymology to the French sign JOUER (play) by representing the two Js (as initialised handshapes). The sign though is performed almost in the same way in other SLs (e.g. Brasilian, Turkish, Indian; cf. SPREADTHESIGN, 2012), which are not related to French Sign Language (LSF), like GSL, within a great geographical distance.

Less frequently, the semantic examination of GSL and ASL demonstrated that the Y-handshape denotes concepts of 'light' in terms of the spectrum of light. Hence, the handshape refers to bright colours such as YELLOW and BLONDE in ASL, and BLUE and BEIGE in GSL (Fig. 8). The result of this comparison corroborates psycholinguistic research that associates closed phonology (e.g. the round vowels $/ \mathrm{o} /$ and $/ \mathrm{u} /$ ) for the same colours (MARKS, 1982; TAMBOVTSEV, 1988). In ASL, the sign YELLOW is also used as the second handshape for the sign GOLD, which, in turn, is used for the sign CALIFORNIA, due to the connection of the state with gold extraction (COSTELLO, 2008; SHAW; DELAPORTE, 2008). In this sign, the Y-handshape etymologically refers to the initialization of the French $<\mathrm{J}>$ from the word jaune (yellow) (SHAW; DELAPORTE, 2008), which, subsequently, leads to the word iaune and thus to Io or Venus (cf. MERTZANI, 2017), whose symbol was the cow as aforementioned.

Figure 8 - The Y-handshape in the domain light and colours

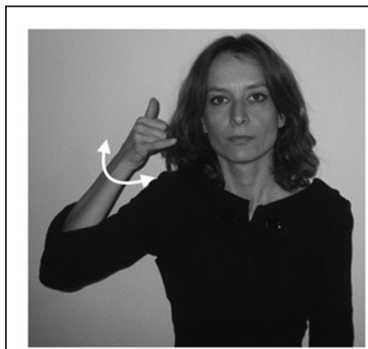

ASL: YELLOW $\mathbf{2}$

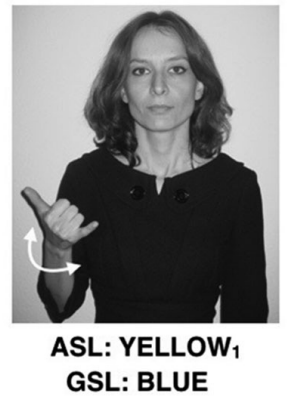

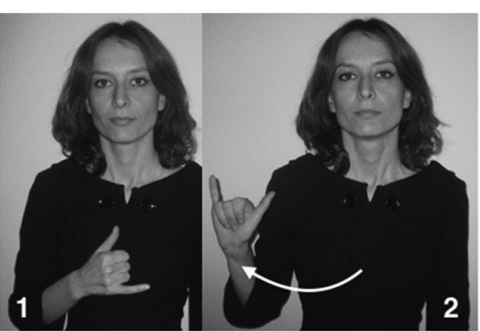

ASL: BLONDE

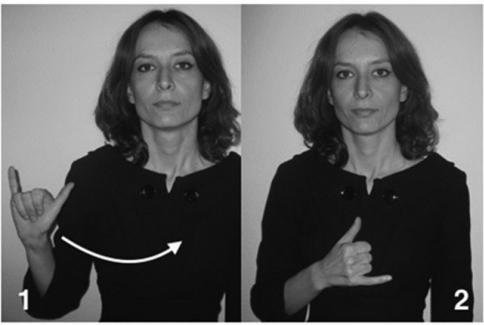

GSL: BEIGE

Source: author's elaboration.

In the 'loss/hurt' domain, the Y-handshape refers to the handling of objects such as in ASL, the sign HANG-BY-A-ROPE, which is executed by both the A-handshape and 
Y-handshape. In this case, the extension of fingers corresponds to the linearity of the referent (e.g. the rope), as it occurs in the 'quantity, measurement and time' domain for MEASURE, SIZE and RULER in ASL (cf. COSTELLO, 2008; SHAW; DELAPORTE, 2015) (Fig. 9). Another mimetic representation is the sign ANTAGONISTIC (cf. CONTRARY, BULLHEADED, CANTANKEROUS), whose Y-handshape represents two opposing horned animals meeting head-on (COSTELLO, 2008), hence corresponding to 'life/animal' and 'head/edge' domains (Fig. 10).

Figure 9 - Examples of Y-handshape use in the domains 'loss/hurt' and 'quantity, measurement and time'

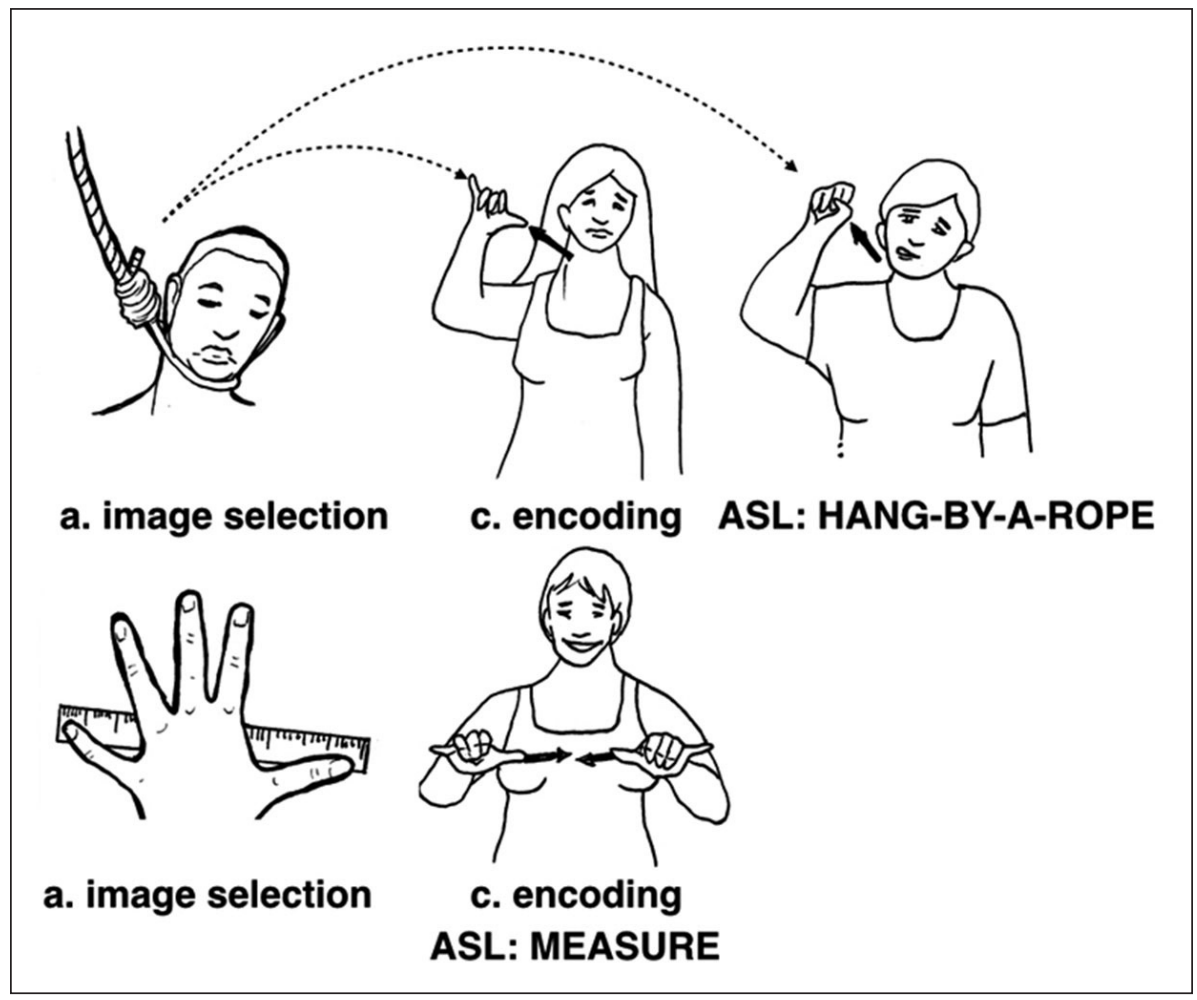

Source: author's elaboration. 
Figure 10 - The Y-handshape in the ASL ANTAGONISTIC and its synonyms

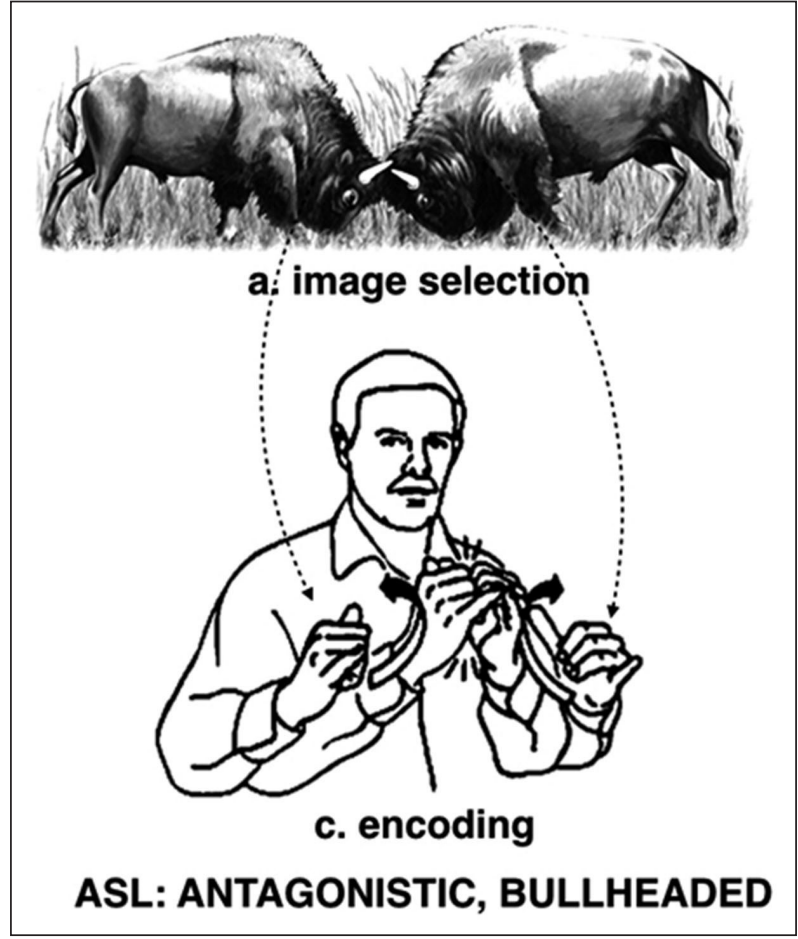

Source: Costello (2008, p.111).

In ASL, IMPOSSIBLE is etymologically connected to its French cognate sign (SHAW; DELAPORTE, 2015), in which the Y-handshape seems to represent the head, hence corresponding to the 'head/edge,' and by extension, to the 'life/animal' domains. The sign under the same concept exists in GSL (e.g. in GSL, IMPOSSIBLE, NEVER), although the execution is different (Fig. 11). Interestingly, the etymology of WRONG in ASL (cf. ACCIDENTALLY, AMISS, BY-MISTAKE; COSTELLO, 2008), also shows its connection to the French sign TROMPER (deceive), which was based on mano cornuta. Moreover, under this same domain of 'loss/hurt,' this connection with mano cornuta is shown for the ASL sign SILLY (SHAW; DELAPORTE, 2015), as well as for the signs IRONY and SARCASTIC (COSTELLO, 2008), which are performed by both the Y-handshape and H-handshape. 
Figure 11 - The Y-handshape in the sign IMPOSSIBLE

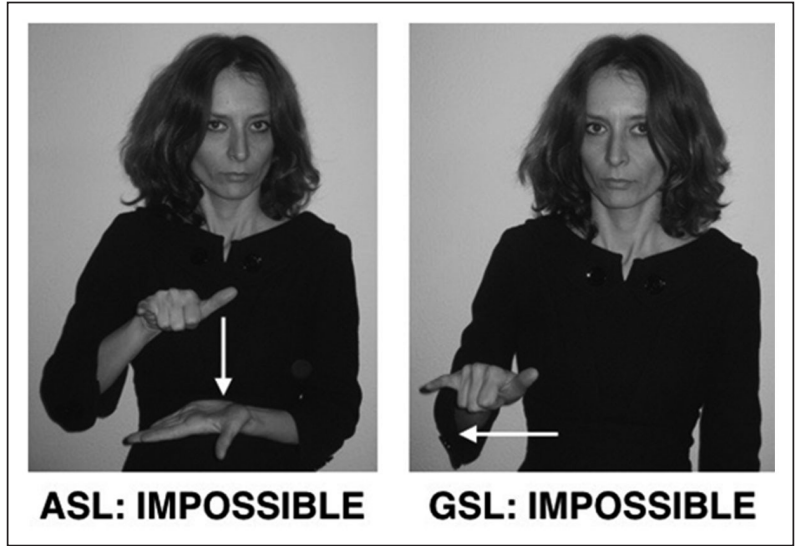

Source: author's elaboration.

Although it is met once in ASL and GSL in the domain 'happiness,' the articulation of the sign ENTERTAINMENT agrees with the sign WALK (cf. motion domain) and its given etymology through the sign PLAY. Additionally, the ASL sign COMICAL/HUMOROUS is etymologically explained by the mano cornuta, thus justifying its closed phonology to the 'head/edge' and/or 'animal/life' domains.

The meaning 'liquids' was found in ASL only, as in the sign DRUNK, in which the Y-handshape represents the physical action of drinking from a bottle. Similar depictions are documented in ASL for the signs LOTION and PERFUME (COSTELLO, 2008), whereas in GSL, the $\AA$-handshape is preferred (e.g. OIL, TO-DRINK) imitating the round shape of bottles, cups, and vases (cf. also BAKER; COKELY, 1980).

\section{Discussion and conclusion}

Although the frequency of the Y-handshape is rare, its comparison in ASL and GSL demonstrated phonological convergence almost under the same semantic domains. In fact, this correspondence seems to be due to the metonymic function of the Y-handshape under the main meaning of a cow. Following the etymology of ASL on LSF, the sign COW is met in the 'earth/land' domain (e.g. SPAIN, NETHERLANDS, CALIFORNIA); in the 'light' domain (GOLD, YELLOW, BLOND); in the 'loss/hurt' domain (e.g. ANTAGONISTIC, IMPOSSIBLE, SILLY, WRONG); and in the domains 'happiness' (COMICAL, HUMOROUS) and 'motion' (ENTERTAINMENT). Likewise, GSL used this sign in the meanings of 'animal/ life,' 'quantity/measure' (e.g. THURSDAY), and in the domains 'light' (BLUE, BEIGE) and 'motion' (PLAY). Under all these meanings, the COW is linked to the ancient handshape of mano cornuta, which was sacred to Venus and Mother Goddess overall. This explanation also confirms the French connection and the etymologies of Y-handshape on the letter $<$ J $>$ (cf. SHAW; DELAPORTE, 2015). 
For example, the etymology of PLAY from jouer ( $>$ Latin iocāri $>$ iocus $>$ AG: $\dot{\eta}$ iv $\gamma \dot{\eta}$ : a shout of joy or pain) leads to cow Io (cf. also i $i \omega$ : exclamation of joy or sorrow), to mano cornuta, and her sistrum, which this study suggests to be represented by the signs WALK (cf. also $i ́ \omega$, to go), and PLAY (and ENTERTAINMENT). Similarly, for the etymology of the French jaune-iaune for the signs YELLOW, GOLD and CALIFORNIA. In these cases, the Y-handshape represents both the cow (its head), and the handling and rotation of the instrument (the sistrum). In fact, the sistrum's handle used to represent the cow face of the goddess (Fig. 12). Moreover, her sacred colours were the ones of this study (e.g. blue ${ }^{11}$ and white) (GUBERNATIS, 1872), which are also denoted in the aloha ${ }^{12}$ meanings (e.g. to shine, white light; cf. ANDREWS, 1922) with which the Hawaiian shaka associates. In other cultures, such as in Australian aborigines (Walmajarri people), the Y-handshape in the sign KUNGA means woman, which also agrees with the meanings under discussion. Again, the connection of the woman with this sign is explained by the ancient representation of the pubic triangle (the uterus and fallopian tubes) as the cow's head (MERTZANI, 2017).

Figure 12 - The association of PLAY with sistrum

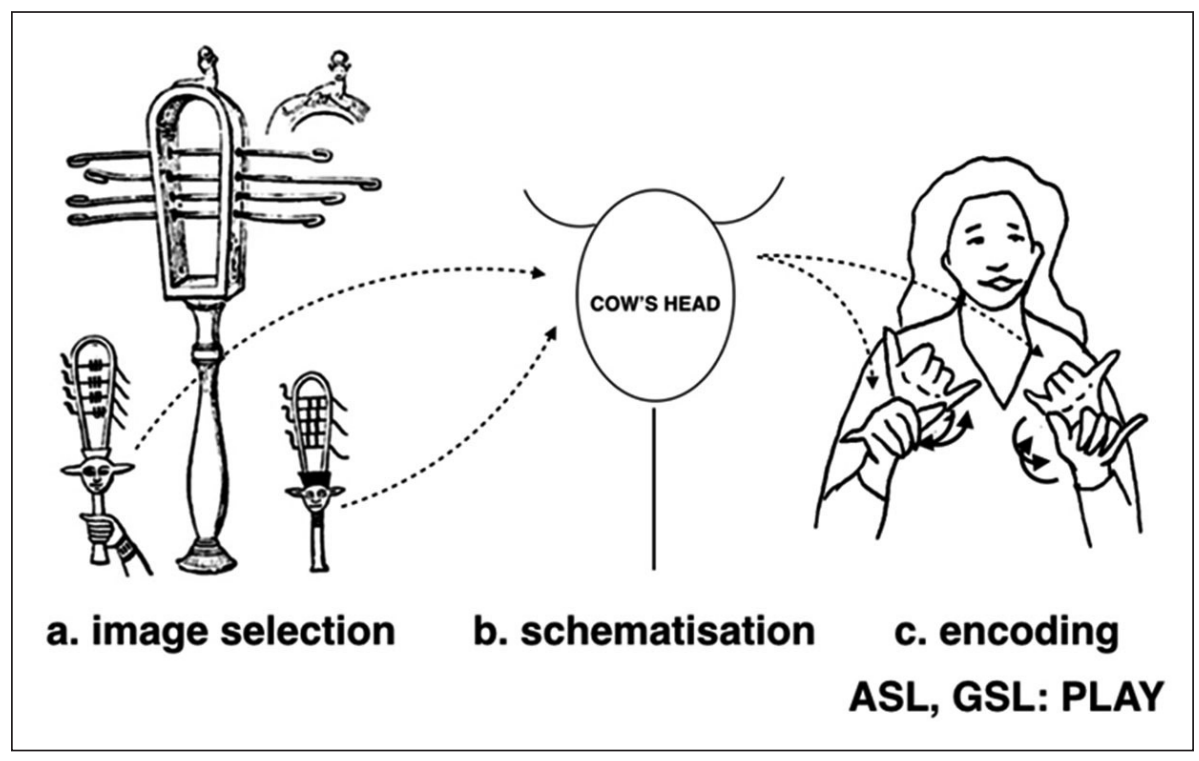

Source: author's elaboration.

Overall, the Y-handshape maps to the forms of its referents. In most cases, it corresponds to the semicircle and/or the U shape of i.e., the sickle moon, the horns,

\footnotetext{
11 In Spanish Sign Language, the blue colour is articulated with both the Y-handshape and H-handshape.

12 The etymology of aloha (and its derivatives, alohi, alohikea, etc.) involves the words: alo, the face; ha, the blue colour; and $h i$, the flowing of water, the sea (ANDREWS, 1922, p.52).
} 
the jaws, and the pipe; in other words, to referents that carry simultaneously roundness and angularity/linearity, or only angularity/linearity (Fig. 13). Concerning the latter, the extended fingers of the Y-handshape correspond to the linear form of i.e., the rope, the ruler, and the razor, a result that reminds of Gibson (1929) arguing about the representation of angularity and/or linearity through roundness but not the other way around. That is, a round form cannot be represented by linear/angular shapes. In this case, the closeness of the Y-handshape is analogous to the closeness of the circle, which, in the lexemes under study, corresponds to i.e., the volume of an obese person, the cylindrical body of the plane, and the handling of the items (the phone, iron, bottle, etc.). This relationship is clearer in signs articulated by both the Y-handshape and the A-handshape (or its allophones), as the second is a complete close handshape, and hence analogous to the circle.

Figure 13 - Signs produced by the Y-handshape as mano cornuta

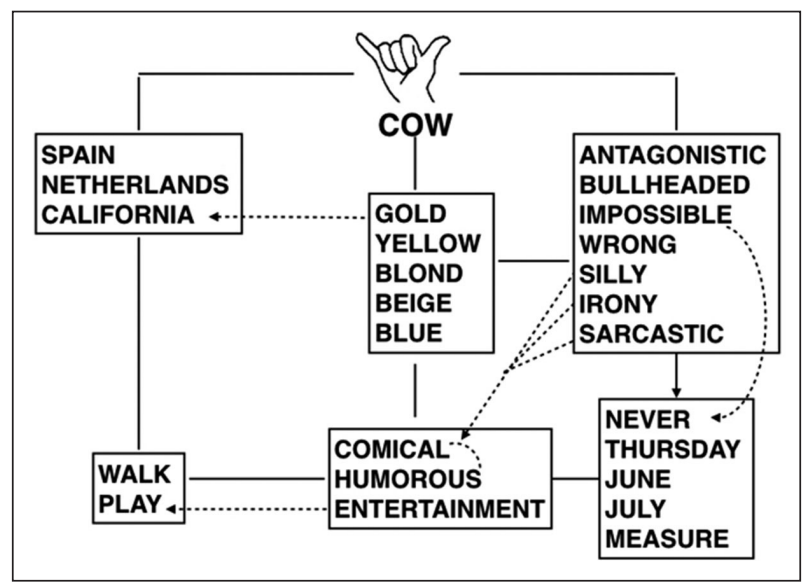

Source: author's elaboration.

There are also few occasions in which the Y-handshape alternates with the $\mathrm{H}$-handshape that also connects to mano cornuta. Due to these associations, the study addresses the need to set up a comparative frame in which linguistics, archaeology and/ or anthropology can provide pertinent evidence for better understanding such crosscultural convergence within a historic continuum. Such analysis, especially where the Y-handshape is considered to represent the letters of spoken languages (e.g. $<J>$ ), suggests a careful examination of the etymology of the lexicalised signs, consulting historical and comparative linguistics. The mano cornuta is an illustrative example, since it shares a historic and cultural past with modern cognate and non-cognate SLs.

Based on abundant archaeological iconography and artifacts, the specific handshape (as a Y-handshape and H-handshape) is recorded not only in Europe and Mediterranean, but also in North, Central and South America, and Asia (China, India, etc.) throughout 
history. Additionally, deaf people used indigenous sign languages in North America before their contact with LSF (MCKEE; KENNEDY, 2000; STOKOE, 2001), while, based on ancient Greek sources (e.g. Plato), deaf people of the era should have been familiar with the context and use of mano cornuta. As a result, throughout the process of diachronic conventionalisation (DEMEY; VAN HERREWEGHE; VERMEERBERGEN, 2008), part of its iconic qualities remained intact, and as their lexicon developed, structural analogies were created (mainly because of lexical polysemy) according to context factors, due to which it lost its original iconicity. Fig. 14 displays such connections in ASL and GSL, based on the results of this study for the Y-handshape.

Figure 14 - Summary of the Y-handshape in the semantic domains

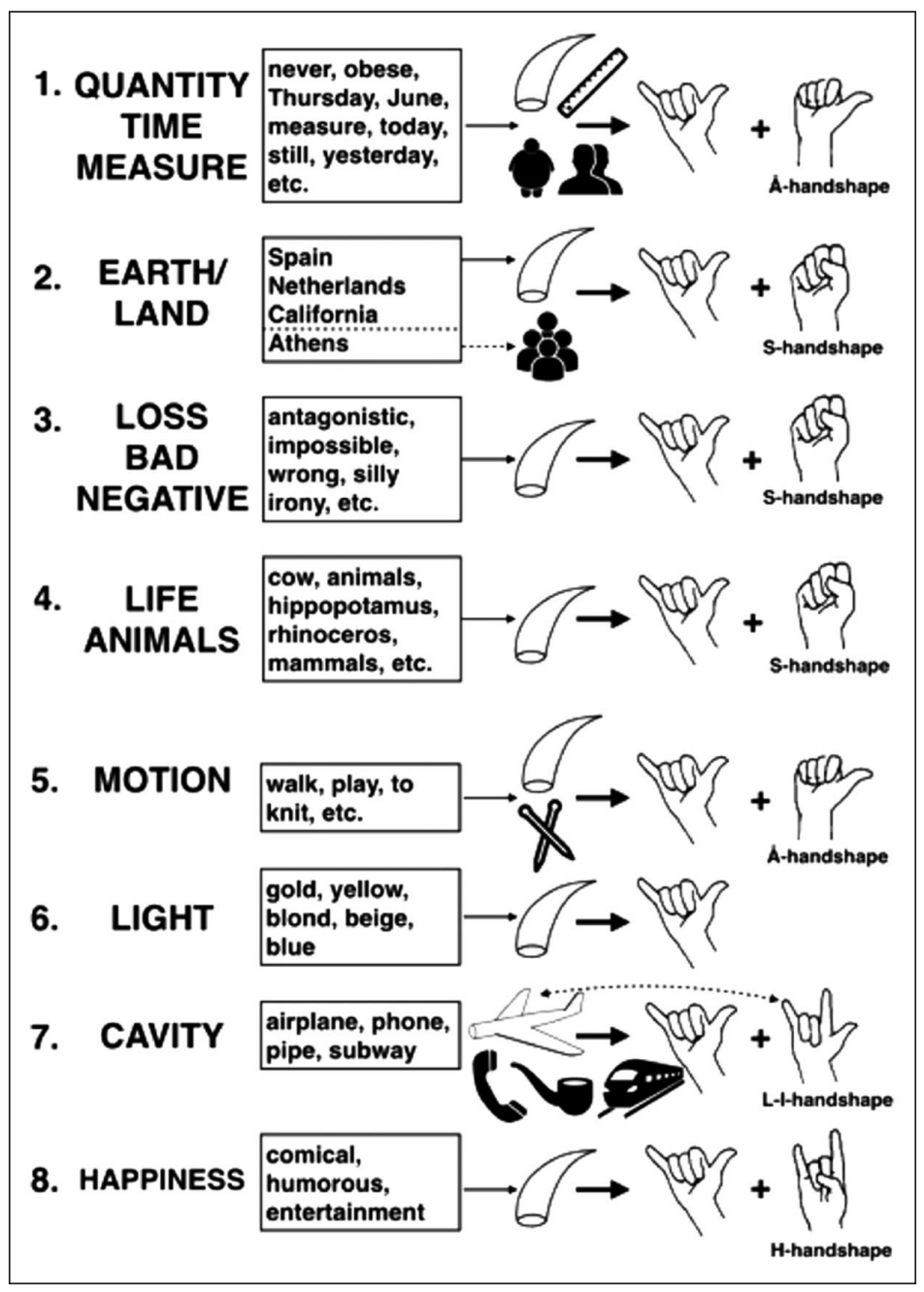

Source: author's elaboration. 
The study was limited to examine the concept categories under which the Y-handshape signs of the two SLs were classified. Thus, the aim was not on revealingon a sign-to-sign comparison (as in the methodology of lexicostatistics) - identical and/or similar signs, mainly because the small sample did not permit such research conduct. However, its close reading methodology allowed the deep understanding of the semantic connections, determining possible historical relations of the signs, and significant analogies in the vocabulary of the two SLs.

\section{Acknowledgement}

This study was funded by CAPES - Coordenação de Aperfeiçoamento de Pessoal de Nível Superior (Code: 42003016039P5). I am grateful to my colleague Mirna Xavier Gonçalves UFPEL, Pelotas - RS Brazil, for her sign language illustrations in this study. She owns the copyright of this work.

MERTZANI, M. A iconicidade da forma de mão Y. Alfa, São Paulo, v.62, n.3, p.617-639, 2018.

- RESUMO: Como parte de um projeto de pesquisa de dois anos, o estudo examina a iconicidade diagramática da forma de mão Y de duas línguas de sinais não-cognatas; a língua de sinais americana e a lingua de sinais grega. Em uma amostra de sessenta e quatro sinais, e através de uma metodologia de leitura próxima, o estudo demonstra a associação da forma de mão especifica com referentes do mundo real que têm simultaneamente forma redonda e angular (por exemplo, cilíndrica, cônica), ou apenas forma angular/linear. Também apoia a sua associação histórica com o antigo signo mano cornuta, abordando sua metonímia em significados relativos à quantidade, terra, vida, perda, luz e cavidade.

- PALAVRAS-CHAVE: forma de mão Y. mano cornuta. iconicidade. língua de sinais americana. lingua de sinais grega.

\section{REFERENCES}

ANDREWS, L. A Dictionary of the Hawaiian language. Honolulu, Hawaii: The Board of Commissioners of Public Archives of the Territory of Hawaii, 1922.

AURACHER, J.; Albers, S.; Zhai, Y.; Gareeva, G.; Stavniychuk, T. P is for Happiness, $\mathrm{N}$ is for Sadness: Universals in Sound Iconicity to Detect Emotions in Poetry. Discourse Processes, n.48, p.1-25, 2011.

BAKER-SHENK, C. L.; COKELY, D. American Sign Language: A Teacher's Resource Text on Grammar and Culture. Washington, DC: Gallaudet University Press, 1980. 
BIEDERMAN, I. Recognition-by-Components: A Theory of Human Image Understanding. Psychological Review, n.94(2), p.115-147, 1987.

BREITMEYER, B. G.; TAPIA, E. Roles of Contour and Surface Processing in Microgenesis of Object Perception and Visual Consciousness. Advances in Cognitive Psychology, n.7, p.68-81, 2011.

COSTELLO, E. American Sign Language Dictionary. New York: Random House, 2008 .

DEMEY, E.; VAN HERREWEGHE, M.; VERMEERBERGEN, M. Iconicity in Sign Languages. In: WILLEMS, K.; DE CUYPERE, L. (Ed.). Naturalness and Iconicity in Language. Amsterdam: John Benjamins Publishing Company, 2008. p.189-214.

EDUCATIONAL POLICY INSTITUTE. Online Dictionary of Concepts in GSL. Athens, Greece: National Strategic Reference Framework ESPA 2007-2013, Operational Programme "Education and Lifelong Learning," 2013. Available in: <http://prosvasimo. gr/el/onlne-lexiko-ennoiwn>. Access in: 1 mar. 2016.

ELWORTHY, F. T. Horns of Honour and Other Studies in the By-Ways of Archaeology. London: John Murray, 1900.

EMMOREY, K. Iconicity as Structure Mapping. Philosophical Transactions of the Royal Society B, n.369, aug. 2014. [Unpaged]. Available in: <http://rstb. royalsocietypublishing.org/content/369/1651/20130301>. Access in: 15 mar. 2016.

FRISBERG, N. Arbitrariness and Iconicity: Historical Change in American Sign Language. Language, n.51(3), p.696-719, 1979.

GIBSON, J. J. The Reproduction of Visually Perceived Forms. Journal of Experimental Psychology, n.12(1), p.1-39, 1929.

GUBERNATIS, A. Zoological Mythology or the Legends of Animals. v.I. London: Trubner \& Co, 1872.

HERLOFSKY, W. J. Iconic Thumbs, Pinkies and Pointers. The Grammaticalization of Animate-Entity Handshapes in Japan Sign Language. In: TABAKOWSKA, E.; LJUNGBERG, C.; FISCHER, O. (Ed.). Insistent Images. Amsterdam, The Netherlands: John Benjamins, 2007. p.37-53.

HINTON, L.; NICHOLS, J.; OHALA, J. J. Introduction: Sound-Symbolism Processes. In: OHALA, J. J.; HINTON, L.; NICHOLS, J. (Ed.). Sound Symbolism. Cambridge, UK: Cambridge University Press, 1994. p.1-12.

KANEKO, M.; SUTTON-SPENCE, R. Iconicity and Metaphor in Sign Language Poetry. Metaphor and Symbol, n.27(2), p.107-130, 2012.

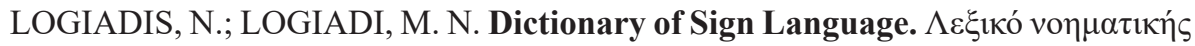
$\gamma \lambda \omega ́ \sigma \sigma \alpha \varsigma$ (in Greek). Athens: Potamitis Press, 1985. 


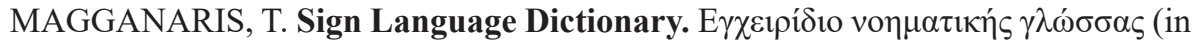
Greek). Thessaloniki: European Social Fund "Employment - HORIZON" \& Aristotle University of Thessaloniki, 1998.

MARKS, L. E. Bright Sneezes and Dark Coughs, Loud Sunlight and Soft Moonlight. Journal of Experimental Psychology: Human Perception and Performance, n.8(2), p.177-193, 1982.

MCKEE, D.; KENNEDY, G. Lexical Comparison of Signs from American, Australian, British, and New Zealand Sign Languages. In: EMMOREY, K.; LANE, H. (Ed.). The Signs of Language Revisited: An Anthology to Honor Ursula Bellugi and Edward Klima. Mahwah, New Jersey: Lawrence Erlbaum Associates, 2000. p.49-76.

MERTZANI, M. Iconicity in Ancient Languages. A Case Study of KA-RA in Greek. Cadernos do LEPAARQ, n.14(27), p.72-88, 2017.

MIALL, D. S. Sounds of Contrast: An Empirical Approach to Phonemic Iconicity. Poetics, n.29, p.55-70, 2001.

NOBILE, L. Words in the mirror: Analysing the sensorimotor interface between phonetics and semantics in Italian. In: MICHELUCCI, P.; FISCHER, O.; LJUNGBERG, C. (Ed.). Iconicity in Language and Literature 10: Semblance and Signification. Amsterdam/Philadelphia: John Benjamins, 2011. p.101-132.

Padden, C.; Meir, I.; Hwang, S.; Lepic, R.; Seegers, S.; Sampson, T. Patterned Iconicity in Sign Language Lexicons. Gesture, n.13(3), p.287-308, 2013.

PERNISS, P.; THOMPSON, R. L.; VIGLIOCCO, G. Iconicity as a General Property of Language: Evidence from Spoken and Signed Languages. Frontiers in Psychology, n.1(227), dec. 2010. Available in: <https://www.ncbi.nlm.nih.gov/pmc/articles/ PMC3153832/>. Access in: 15 mar. 2016.

SHAW, E.; DELAPORTE, Y. A Historical and Etymological Dictionary of American Sign Language. Washington, DC: Gallaudet University Press, 2015.

SPREADTHESIGN. Örebro, Sweden: European Sign Language Centre, 2012. Available in: <www.spreadthesign.com>. Access in: 1 mar. 2016.

STOKOE, W. C. Language in Hand. Why Sign Came Before Speech. Washington, DC: Gallaudet University Press, 2001.

SUPALLA, T. Revisiting Visual Analogy in ASL Classifier Predicates. In: EMMOREY, K. (Ed.). Perspectives von Classifier Constructions in Sign Language. Mahwah, New Jersey: Lawrence Erlbaum Associates, 2003. p.249-258.

TAMBOVTSEV, Y. A. Associations of Colors with Russian Vowels. Bulletin of the Psychonomic Society, n.26(4), p.353-354, 1988. 
TANG, G. Verbs of Motion and Location in Hong Kong Sign Language: Conflation and lexicalization. In: EMMOREY, K. (Ed.). Perspectives on Classifier Constructions in Sign Language. Mahwah, New Jersey: Lawrence Erlbaum Associates, 2003. p.143-166.

TANG, G.; YANG, GU. Events of Motion and Causation in Hong Kong Sign Language. Lingua, n.117, p.1216-1257, 2007.

TAUB, S. F. Language from the Body: Iconicity and Metaphor in American Sign Language. Cambridge: Cambridge University Press, 2001.

TAUB, S. F. Language from the Body: Iconicity and Metaphor in American Sign Language. Cambridge: Cambridge University Press, 2004.

TENNANT, R. A.; GLUSZAK BROWN, M. The American Sign Language Handshape Dictionary. Washington, D.C.: Gallaudet University Press, 1998.

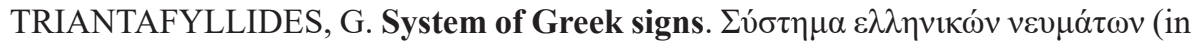
Greek). Thessaloniki: "The friends of the Deaf in Thessaloniki" Club, 1990.

VAN DER KOOIJ, E.; CRASBORN, O. A. Chapter 11: Phonology. In: BAKER, A.; VAN DEN BOGAERTE, B.; PFAU, R.; SCHERMER, T. (Ed.). The Linguistics of Sign Languages: An Introduction. Amsterdam: John Benjamins, 2016. p.251-278.

WAUGH, L. R. Degrees of Iconicity in the Lexicon. Journal of Pragmatics, n.22, p.55-70. 1994. 


\section{Appendix}

\begin{tabular}{|c|c|}
\hline ASL SIGNS & GSL SIGNS \\
\hline OH-I-SEE & COW \\
\hline YELLOW & IMPOSSIBLE \\
\hline STAY, REMAIN, STILL & AIRPLANE \\
\hline ME-TOO, IN-COMMON, SAME, SIMILAR & NEPHEW \\
\hline COW, BULL & TAKE-A-WALK \\
\hline DRUNK & ENTERTAINMENT \\
\hline BLOND & ANIMALS \\
\hline TELEPHONE & BLUE \\
\hline HOLLAND, DUTCH, THE-NETHERLANDS & COUSIN \\
\hline SILLY, ABSURD, FOLLY, FOOLISH, RIDICULOUS & PLAY, TO-PLAY \\
\hline HANG-BY-A-ROPE & THURSDAY \\
\hline SHAVE & PIPE \\
\hline ERROR, WRONG & NEVER \\
\hline YESTERDAY & TO-LAND (airplane) \\
\hline THAT-ONE, THAT & RELATIVES \\
\hline IMPOSSIBLE & TOILET, WC \\
\hline HIPPOPOTAMUS & STILL, YET \\
\hline IRON-CLOTHES & ETERNITY, CONTINUOUSLY \\
\hline MEASURE & TO-KNIT \\
\hline NEW-YORK & BULL \\
\hline RHINOCEROS & SPAIN \\
\hline SUBWAY & JUNE \\
\hline WHY & SLOW \\
\hline PLAY & WALK (to-take-a-walk) \\
\hline NOW, PRESENTLY & ATHENS \\
\hline $\begin{array}{l}\text { CONTRARY, ANTAGONISTIC, BULLHEADED, } \\
\text { CANTANKEROUS }\end{array}$ & MAMMALS \\
\hline MEASURE, RULER, SIZE & PREY \\
\hline STILL, YET & BEIGE \\
\hline \multicolumn{2}{|l|}{ UNIFORM, UNIVERSAL } \\
\hline \multicolumn{2}{|l|}{ humorous, comical } \\
\hline \multicolumn{2}{|l|}{ drafting, engineering } \\
\hline \multicolumn{2}{|l|}{ fat, obese } \\
\hline \multicolumn{2}{|l|}{ country } \\
\hline \multicolumn{2}{|l|}{ big-word } \\
\hline \multicolumn{2}{|l|}{ swear, curse } \\
\hline today & \\
\hline
\end{tabular}

Received on 11 January, 2018

Approved on 12 May, 2018 
